\title{
DoIs Exorcismos PARA AfAstar o Novo GÉnio MALIGNO
}

\author{
DOMINGOS FARIA
}

\begin{abstract}
Our main aim in this paper is to develop two solutions or exorcisms to ward off the new evil demon problem against epistemic reliabilism. The first solution is designated as "indexical reliabilism" and the second as "normal-conditions reliabilism". We will argue that the second solution is more plausible than the first. We will also argue that this second solution, if properly developed, can respond well to several recent objections. Therefore, reliabilism has good ways of dealing with the new evil demon problem.
\end{abstract}

Keywords: New evil demon; process reliabilism; indexical reliabilism; nomal-conditions reliabilism.

Numa formulação simples, com o fiabilismo dos processos defende-se que uma crença $p$ tem justificação ou um relevante estatuto epistémico positivo para um sujeito $S$ só se a crença $p$ de $S$ resulta de um processo de formação de crenças fiável ou de processos de formação de crenças fiáveis. ${ }^{1}$ Uma objeção comum a esse tipo de fiabilismo epistémico visa questionar a necessidade da condição fiabilista para haver justificação ou um grau significativo de estatuto epistémico positivo. A esta objeção Sosa (1991, p.132) chamou de "novo problema do génio maligno". Isto porque já há um antigo problema do génio maligno em que se procura argumentar que podemos ser enganados por um génio maligno e se tal for o caso, então não podemos realmente saber, entre outros, proposições sobre o mundo exterior (como a de que tenho mãos, etc.). Deste modo, o problema antigo do génio maligno usa essa hipótese num argumento para o ceticismo. ${ }^{2}$ Contudo, o novo problema do génio maligno não é diretamente sobre o ceticismo, mas sim sobre uma suposta consequência do fiabilismo que implica que as vítimas do génio maligno, ou de outro cenário cético similar (como o do cérebro numa cuba), nunca podem estar justificadas. Ora, para se bloquear essa consequência contraintuitiva, os críticos do fiabilismo negam que a condição da fiabilidade seja necessária para a justificação. Uma das primeiras formulações deste novo problema foi apresentada por Lehrer e Cohen (1983, pp.192-193) da seguinte forma: ${ }^{3}$

Imagine que, sem o sabermos, os nossos processos cognitivos, aqueles envolvidos na perceção, memória e inferência, não são fiáveis por causa das manobras de um génio poderoso ou cientista malévolo. Daí resultaria na perspetiva fiabilista que sob tais condições as crenças geradas por tais processos não seriam justificadas. Este resultado é inaceitável. A verdade da hipótese do génio também implica que as nossas experiências e os nossos

Principia 21(3): 461-471 (2017).

Published by NEL — Epistemology and Logic Research Group, Federal University of Santa Catarina (UFSC), Brazil. 
raciocínios são tais como seriam caso os nossos processos fossem fiáveis e, portanto, nós seríamos tão bem justificados em acreditar no que acreditamos tanto se a hipótese do génio fosse verdadeira como se fosse falsa. Contrariamente ao fiabilismo, afirmarmos que sob as condições da hipótese do génio as nossas crenças seriam justificadas num sentido epistémico.

Por outras palavras, Lehrer e Cohen convidam-nos a imaginar duas contrapartes epistémicas $S$ e $S^{*}$ de tal forma que $S^{*}$ acredita exatamente o que $S$ acredita, tem experiências fenomenologicamente indistinguíveis de $S$, recorda-se de tudo o que $S$ se recorda, está disposto a raciocinar da mesma forma que $S$, entre outros. Pode-se até supor que $S$ e $S^{*}$ têm os mesmos estados mentais não factivos desde o nascimento. Contudo, suponha-se que $S^{*}$ é enganado por um génio maligno (doravante GM), ${ }^{4}$ enquanto $S$ não o é. Isto porque $S^{*}$ está num mundo $w$ do GM (doravante $w_{G M}$ ), enquanto $S$ está no mundo atual (doravante $w_{@}$ ). Por causa disso, em $w_{G M}$, o GM cria p.e. perceções não verídicas de objetos físicos na mente de $S^{*}$, sendo falsas todas as suas crenças percetivas (apesar de qualitativamente idênticas às de $S$ ); todavia, supostamente grande parte das experiências percetivas de $S$ em $w_{@}$ são verídicas. Desta forma, podemos supor que enquanto as crenças de $S$ são produzidas por processos fiáveis, as crenças de $S^{*}$ resultam de processos completamente não fiáveis (por causa do GM enganador). ${ }^{5}$ Ora, de acordo com o fiabilismo, isto implica que $S$ está justificado, mas $S^{*}$ não está justificado nas suas crenças. No entanto, isto parece contraintuitivo, pois tendo em conta que $S^{*}$ tem os mesmos estados mentais não factivos de $S$, que as suas experiências do mundo exterior são qualitativamente indistinguíveis das de $S$, bem como atendendo que $S^{*}$ é agente epistémico tão responsável como $S$ (i.e. ambos não cometem falácias, raciocinam com cuidado, acreditam com base em evidência, etc.), então $S^{*}$ está tão justificado nas suas crenças como $S$ está nas suas. Ora, essa é a intuição básica subjacente ao problema do novo GM. Com base neste raciocínio, e para clarificar melhor o problema, pode-se formular o argumento do novo génio maligno tal como se segue: ${ }^{6}$

(1) As crenças de $S^{*}$ em $w_{G M}$ são tão justificadas como as crenças de $S$ em $w_{@}$. [Premissa, intuição do novo GM]

(2) As crenças de $S$ em $w_{@}$ são justificadas. [Premissa, suposição]

(3) $\therefore$ As crenças de $S^{*}$ em $w_{G M}$ são justificadas. [De 1 e 2]

(4) A crença $p$ de um dado sujeito é justificada só se $p$ é produzida por um processo fiável. [Premissa, condição fiabilista]

(5) $\therefore$ As crenças $S^{*}$ são produzidas por um processo fiável. [De 3 e 4]

Este argumento é válido, mas a conclusão (5) é obviamente falsa ou, pelo menos, bastante contraintuitiva. Assim, temos de rejeitar pelo menos uma das premissas. Aqueles que argumentam contra o fiabilismo, como Lehrer (1983), Cohen (1984), 
Pollock (1984), Foley (1985), Feldman (1985), rejeitam a premissa (4). E se essa opção for a mais adequada, isso mostra que a fiabilidade não é uma condição necessária para a justificação. Será que o fiabilista tem alguma resposta plausível para este problema? Será possível manter a intuição subjacente ao novo génio maligno, a premissa (1), ao mesmo tempo que se defende a condição fiabilista, a premissa (4)? Para responder a este desafio vamos apresentar duas tentativas de solução que nos parecem prometedoras. ${ }^{7}$ Todavia, iremos argumentar que a segunda proposta é melhor do que a primeira.

\section{Primeiro exorcismo: fiabilismo indexical}

A primeira resposta que pretendemos analisar, conhecida como "fiabilismo indexical", é sugerida por Comesaña $(2002 ; 2010)$ ao propor que clarifiquemos melhor a premissa (4), i.e. a condição de fiabilidade. Isto porque, ao afirmar-se " $p$ é produzida por um processo fiável", leva-nos a questionar: mas fiável onde? Para Comesaña o que é relevante é que processo em questão seja fiável atualmente. ${ }^{8}$ Todavia, "atualmente" é um termo indexical (referindo-se ao mundo em que foi proferido), bem como é um termo cuja semântica apropriada é bidimensional. Desta forma, seguindo a semântica bidimensional de Stalnaker (1999, pp.78-95), há duas proposições diferentes associadas com a atribuição de justificação. A primeira, a "proposição diagonal", diz que a crença é produzida por um processo que é fiável no mundo em que é acreditada. A segunda, a "proposição horizontal", diz que a crença é produzida por um processo que é fiável em seja qual for o mundo em que a proposições é considerada.

Tendo em conta este fiabilismo indexical e semântica bidimensional, as crenças das vítimas do GM, como $S^{*}$, podem ser horizontalmente justificadas, embora não sejam diagonalmente justificadas. E as crenças de $S^{*}$ estão horizontalmente justificadas na medida em que essas crenças são produzidas por processos que são fiáveis no nosso mundo $w_{@}$ e no mesmo sentido que as nossas crenças são justificadas. Contudo, as crenças de $S^{*}$ não são diagonalmente justificadas uma vez que tais crenças não são produzidas por processos fiáveis em $w_{G M}$. Deste modo, há um sentido em que as vítimas do GM podem estar justificadas, embora também há um outro sentido no qual elas não podem estar justificadas (o que permite capturar a intuição de que as vítimas do GM não podem ter conhecimento). ${ }^{9}$ O problema, então, com o argumento acima do novo GM parece ser o de cometer a falácia do equívoco por não distinguir duas diferentes leituras do termo "justificação". Assim, por um lado, se lermos no argumento o termo "justificação" como "justificação diagonal”, a premissa (1) será falsa uma vez que apesar das crenças de $S$ serem diagonalmente justificadas, as crenças de $S^{*}$ não o são. Mas, por outro lado, se lermos "justificação" como "justificação horizontal", a premissa (1) será verdadeira, mas aí também a conclusão será

Principia 21(3): 461-471 (2017). 
verdadeira; ou seja, o que se conclui é que as crenças de $S^{*}$ em $w_{G M}$ são produzidas por um processo que é fiável no nosso mundo $w_{@}$. Portanto, de uma forma ou de outra, evita-se o problema do novo GM.

Esta via de resposta ao problema do novo GM parece à primeira vista bastante apelativa. Todavia, há algumas objeções fortes, como as de Ball e Blome-Tillmann (2013), que disputam a forma como Comesaña utiliza a semântica bidimensional de Stalnaker. Por exemplo, eles sustentam que, "de acordo com o bidimensionalismo de Stalnaker, normalmente não é o caso que ambas as leituras [diagonal e horizontal] estão disponíveis num mesmo contexto conversacional. Mas isso é requerido para a solução de Comesaña do Novo Génio Maligno. (...) Se ambas as leituras não estiverem disponíveis ao mesmo tempo, o diagnóstico de Comesaña que o Novo Génio Maligno comete a falácia do equívoco falhará" (2013, pp.1322-23). Além disso, Ball e Blome-Tillmann procuram mostrar que a forma como Comesaña concebe a diferença entre justificação horizontal e diagonal não se segue da semântica bidimensional de Stalnaker. ${ }^{10}$ Outras críticas ao fiabilismo indexical não têm tanto a ver com a semântica bidimensional, mas sim com as suas consequências supostamente contraintuitivas, tal como defende Graham (2016, pp.96-97). Isto porque se "atual" é um termo indexical, então tal como vimos se consideramos o nosso mundo como o mundo atual podemos dizer que as vítimas do GM têm justificação horizontal. Contudo, a partir da perspetiva das vítimas do GM (do seu mundo de elocução), o mundo

$w_{G M}$ é o seu mundo atual e, dessa forma, as suas crenças não são horizontalmente justificadas. Assim, as crenças das vítimas do GM seriam ao mesmo tempo horizontalmente justificadas e horizontalmente não-justificadas, o que é uma conclusão que parece bizarra.

\section{Segundo exorcismo: fiabilismo das condições normais}

Mas há uma outra solução prometedora para a problema do novo GM e que não recorre a uma semântica bidimensional e indexical, mas sim ao conceito de fiabilidade em circunstâncias apropriadas ou em condições normais. Tal como na resposta anterior, esta via de solução (desenvolvida por Bergmann e Graham) começa por clarificar melhor a condição de fiabilidade, ou seja, a premissa (4). Por exemplo, para Bergmann (2006, pp.141-143) o que é relevante para a justificação de uma dada crença é que essa crença resulte de um mecanismo cognitivo que é fiável nos ambientes para os quais foi 'projetado'. Ora, isso implica que, dado que $S^{*}$ tem um plano de conceção cognitivo semelhante a $S$ e que funciona apropriadamente, as crenças de $S^{*}$ podem estar justificadas na medida em que tais crenças resultam de mecanismos cognitivos que seriam fiáveis em ambientes para os quais eles são projetados para operar (tal como acontece com $S$ ). E essa conclusão, ao contrário de (5), já não será falsa.

Principia 21(3): 461-471 (2017). 
De forma muito semelhante, Graham (2016, pp.100-104) sustenta que a condição de fiabilidade, a premissa (4), deve ser lida da seguinte forma: em todas as possíveis circunstâncias $C$, uma crença é justificada em $C$ só se o processo psicológico que causou ou sustentou a crença fiavelmente produz crenças verdadeiras em condições normais. Desta forma, Graham sugere que em vez da fiabilidade ser relativizada a "mundos" (como na proposta anterior do fiabilismo indexical), deve ser relativizada a "circunstâncias" ou "condições". Além disso, em vez de se relativizar a fiabilidade relevante ao mundo "atual", relativiza-se às circunstâncias ou condições "normais" ou "naturais" (que não são necessariamente as circunstâncias atuais). Mas o que são condições normais? Aqui Graham oferece uma caracterização muito semelhante à noção de plano de conceção de Bergmann e Plantinga; deste modo, as condições normais são os ambientes para os quais as capacidades ou processos em questão foram concebidos (naturalmente ou não). ${ }^{11}$ Ora, esta forma de interpretar a condição de fiabilidade permite dar uma resposta supostamente plausível para o problema do novo GM. Isto porque, apesar de $S$ estar presentemente em condições normais e $S^{*}$ não estar nessas condições, as crenças de $S$ e $S^{*}$ são ambas justificadas na medida em que eles usam as mesmas capacidades humanas normalmente funcionais de formação de crenças, as quais produzem fiavelmente crenças verdadeiras em circunstâncias normais para os seres humanos. ${ }^{12}$ Desta perspetiva a conclusão que se segue no argumento do GM é que as crenças $S^{*}$ são produzidas por um processo fiável em condições normais. Todavia, ao contrário de (5), esta conclusão não será falsa, evitando-se dessa forma o problema do novo GM. ${ }^{13}$

\section{Objeções e Resposta}

Consideramos que a estratégia do fiabilismo das condições normais é provavelmente a proposta mais plausível para o problema no novo GM. Contudo, é possível argumentar que não é claro que esta proposta resolva inteiramente esse problema. Por exemplo, Fumerton (2015, p.124) procura mostrar que esta estratégia tem "a consequência contraintuitiva (pelo menos da perspetiva internista) que alguém com a infelicidade de ter sido projetado por um demónio para o propósito das manobras demoníacas teria crenças epistemicamente injustificadas". Mas, se as experiências desse sujeito são exatamente como são as nossas, Fumerton sustenta que ainda assim parece intuitivo atribuir crenças justificadas a esse sujeito (mesmo que as suas crenças não sejam fiáveis em circunstâncias normais ou nos ambientes para os quais foi concebido). ${ }^{14}$ Por outras palavras, se um sujeito $S^{\#}$ foi concebido por um GM para formar crenças falsas no ambiente para o qual ele foi projetado, então os processos de $S^{\#}$ não são fiáveis em condições normais. Ora, isso implica que as crenças de $S^{\#}$ nunca podem ser justificadas (quer esteja em $w_{M G}$ ou em $w_{@}$ ). Contudo, se 
$S^{\#}$ tem os mesmos estados internos (experiências, evidência, etc.) que $S$, então parece contraintuitivo sustentar que $S^{\#}$ nunca pode estar justificado nas suas crenças. Afinal, será $S^{\#}$ culpado por formar as crenças daquela forma? Serão as suas crenças acidentais a partir da própria perspetiva de $S^{\#}$ ?

Esta última objeção não se opõe diretamente à solução de que os sujeitos $S$ e $S^{*}$ têm ambos justificação por usarem os mesmos processos que são fiáveis em condições normais. Pelo contrário, apenas critica o facto de tal solução não atribuir qualquer justificação a $S^{\#}$ que em condições normais não tem processos fiáveis, apesar de ter os mesmos estados internos que $S^{*}$ ou $S$. Assim, ainda que o fiabilismo das condições normais apresente uma resposta prometedora para o novo GM, essa solução parece incompleta para resolver outros casos similares. Para resolver este problema e para termos uma solução mais completa pensamos que é relevante estabelecer uma distinção entre justificação subjetiva e justificação objetiva. A razão dessa distinção parte da ideia de que o estatuto epistémico positivo é pelo menos constituída por uma componente subjetiva e uma componente objetiva. ${ }^{15}$ Deste modo, o estatuto epistémico positivo é uma função de como as coisas parecem a partir da perspetiva do sujeito, bem como a forma como as coisas são na realidade.

Por um lado, a componente subjetiva do estatuto epistémico positivo, a que chamamos justificação subjetiva, tem a ver com o facto da crença ser bem-formada a partir da perspetiva do sujeito ou de primeira-pessoa e, com base no evidencialismo epistémico, pode ser formulada desta forma: uma crença $p$ é subjetivamente justificada para $S$ sse $p$ é uma resposta apropriada à evidência $E$ de $S$ e $S$ não tem derrotadores não-derrotados de $p \cdot{ }^{16} \mathrm{~A}$ motivação principal para se adicionar este tipo de justificação na nossa teoria do estatuto epistémico positivo prende-se com a questão de permitir lidar facilmente com o problema da sorte epistémica subjetiva. ${ }^{17}$ Contudo, é argumentável que esse tipo de justificação apesar de necessário não é de forma alguma suficiente para um mais relevante ou elevado estatuto epistémico positivo, uma vez que não assegura a condução à verdade. ${ }^{18}$ Assim, por outro lado, há igualmente uma componente objetiva do estatuto epistémico positivo, a que chamamos justificação objetiva, que tem a ver com a crença ser bem-formada a partir de uma perspetiva panorâmica ou de terceira-pessoa e, com base em teorias externistas, tal como o fiabilismo e a função apropriada, pode ser formulada deste modo: uma crença $p$ é objetivamente justificada para $S$ sse $p$ resulta em $S$ de um processo da forma 'produzir $p$ com base na evidência $E$ e num módulo cognitivo apropriadamente funcional de $S$ ' que é fiável em condições normais. Por outras palavras, a probabilidade condicional objetiva de $p$ ser verdadeira, dado a evidência $E$ e a função apropriada de $S$, é alta em condições normais.

Com base nesta distinção, e como resposta à objeção acima de Fumerton, pode-se acomodar a intuição de que as crenças de $S^{\#}$ podem estar de alguma forma justificadas. Nomeadamente, tais crenças podem ter justificação subjetiva na medida em que 
$S^{\#}$ forma as suas crenças com base na sua evidência, de forma responsável, etc. No entanto, uma vez que $S^{\#}$ foi concebido por um GM para formar sistematicamente crenças falsas no ambiente para qual ele foi projetado, essas crenças de $S^{\#}$ não têm qualquer justificação objetiva. Ou seja, as crenças de $S^{\#}$ não resultam de processos fiáveis em condições normais. Ao contrário disso, no argumento original do novo GM, as crenças dos sujeitos $S^{*}$ e $S$ têm justificação subjetiva e objetiva. Mas como é que as crenças de $S^{*}$ em $w_{G M}$ podem ter justificação objetiva? Tal como vimos acima, essas crenças de $S^{*}$ são objetivamente justificadas porque resultam de um processo relevante de formação de crenças que é fiável em condições normais e tem um mecanismo cognitivo que funciona apropriadamente (exatamente com o mesmo plano de conceção de $S$ ). Contudo, apesar das crenças de $S^{*}$ e $S$ estarem justificadas subjetiva e objetivamente, também temos a intuição de que o estatuto epistémico das crenças de $S^{*}$ é menor do que as de $S$. Afinal, ao contrário das crenças de $S$, as crenças de $S^{*}$ não podem ser classificadas como conhecimento. Então, como acomodar com esta intuição? Isso indicia que haver justificação subjetiva e objetiva não basta para se ter um estatuto epistémico positivo suficiente para o conhecimento, sendo que a diferença crucial entre $S^{*}$ e $S$ parece residir no ambiente epistémico. Assim, o estatuto epistémico das crenças de $S^{*}$ é menor do que as de $S$ uma vez que o ambiente epistémico em que $S^{*}$ formou as suas crenças não é favorável (afinal é um ambiente com um GM enganador) ${ }^{19}$ enquanto o ambiente de $S$ é favorável.

Em suma, um fiabilismo das condições normais, apropriadamente desenvolvido, consegue lidar com o novo problema do GM, pois permite-nos concluir que as crenças de $S, S^{*}$, e $S^{\#}$ têm igualmente um estatuto epistémico positivo, mas em diferentes graus. As crenças de $S^{\#}$ são apenas subjetivamente justificadas, tendo assim um grau mínimo de estatuto epistémico positivo. As crenças de $S^{*}$ são subjetiva e objetivamente justificadas, mas não são produzidas num ambiente epistémico presentemente favorável, tendo dessa forma um grau intermédio de estatuto epistémico positivo. Apenas as crenças de $S$ têm o grau mais elevado de estatuto epistémico positivo, pois as suas crenças são subjetiva e objetivamente justificadas, bem como são produzidas num ambiente epistémico presentemente favorável. Desse modo, as crenças de $S$ têm estatuto epistémico positivo suficiente para serem conhecimento. Com estes graus ou níveis de estatuto epistémico positivo conseguimos exorcizar com plausibilidade o novo GM.

\section{Referências}

Ball, B.; Blome-Tillman, M. 2013. Indexical Reliabilism and the New Evil Demon. Erkenntnis 78: 1317-1336.

Bergmann, M. 2006. Justification without Awareness: A Defense of Epistemic Externalism. Oxford University Press.

Principia 21(3): 461-471 (2017). 
BonJour, L.; Sosa, E. 2003. Epistemic Justification: Internalism vs. Externalism, Foundations vs. Virtues. Blackwell Publishing.

Carter, A. Palermos, O. 2016. Epistemic Internalism, Content Externalism and the Subjective/Objective Justification Distinction. American Philosophical Quarterly 53: 231-244.

Cohen, S. 1984. Justification and Truth. Philosophical Studies 46: 279-296.

Comesaña, J. 2002. The Diagonal and the Demon. Philosophical Studies 110: 249-266.

- 2010. Evidentialist Reliabilism. Noûs 94: 571-601.

Feldman, R. 1985. Reliability and Justification. The Monist 68: 159-174.

Foley, R. 1985. What's Wrong with Reliabilism?. The Monist 68: 188-202.

Fumerton, R. 2015. Knowledge, Thought, and the Case for Dualism. Cambridge University Press.

Goldman, A. 1986. Epistemology and Cognition. Harvard University Press.

- 1988. Strong and Weak Justification. Philosophical Perspectives 2: 51-69.

- 2002. Pathways to Knowledge: Private and Public. Oxford University Press.

Graham, P. 2016. Against Actual-World Reliabilism: Epistemically Correct Procedures and Reliably True Outcomes. In: Vargas (ed.) Performance Epistemology: Foundations and Applications, pp.83-105. Oxford University Press.

Greco, J. 1999. Agent Reliabilism. Philosophical Perspectives 13: 273-296.

- 2000. Putting Skeptics in Their Place. Cambridge University Press.

- 2014. Justification Is Not Internal. In: Steup et al. (eds.) Contemporary Debates in Epistemology, pp. 325-336. West Sussex: Wiley-Blackwell.

Lackey, J. 2008. Learning from Words: Testimony as a Source of Knowledge. Oxford University Press.

Lehrer, K.; Cohen, S. 1983. Justification, Truth, and Knowledge. Synthese 55: 191-207.

Littlejohn, C. 2009. The New Evil Demon Problem. In: Fieser; Dowden (eds.) Internet Encyclopedia of Philosophy. <http://www.iep.utm.edu/evil-new/>

Plantinga, A.; Tooley, M. 2008. Knowledge of God. Blackwell Publishing.

Pollock, J. 1984. Reliability and Justified Belief. Canadian Journal of Philosophy 14: 103-114.

Sosa, E. 1991. Knowledge in Perspective. Cambridge University Press.

- 1993. Proper Functionalism and Virtue Epistemology. Noûs 27: 51-65. 400 .

Stalnaker, R. 1999. Context and Content. Oxford University Press.

Vahid, H. 2005. Epistemic Justification and the Skeptical Challenge. Palgrave Macmillan.

- 2010. Externalism/Internalism. In: Pritchard et al. (eds.) The Routledge Companion to Epistemology, pp.144-155. Routledge.

DOMINGOS FARIA

Universidade de Lisboa

Faculdade de Letras

Centro de Filosofia, LanCog

df@domingosfaria.net 


\section{Notas}

${ }^{1}$ Para uma introdução geral ao "fiabilismo dos processos" veja-se, p.e., Goldman (1986) e Sosa (2001).

${ }^{2}$ Sendo $M$ a proposição 'eu tenho duas mãos', HC a proposição descrita por alguma hipótese cética (como a de que somos enganados por um génio maligno, ou de que somos um cérebro numa cuba, etc), e $K s \phi$ a abreviatura de 'eu sei que $\phi$ ', pode-se validamente deduzir um ceticismo acerca do mundo exterior da seguinte forma:

(1) $[K s M \wedge K s(M \rightarrow \neg H C)] \rightarrow K s \neg H C$

(2) $K s(M \rightarrow \neg H C)$

(3) $\neg K s \neg H C$

(4) $\therefore \neg[K s M \wedge K s(M \rightarrow \neg H C)]$ (de 1 e 3 , por modus tollens)

(5) $\therefore \neg K s M$ (de 2 e 4 , por silogismo conjuntivo)

${ }^{3}$ Essa mesma ideia é formulada de forma muito similar em Cohen (1984, p.281).

${ }^{4}$ Caso seja pertinente, em vez do génio maligno pode-se recorrer ao caso do cérebro numa cuba. Os resultados são iguais.

${ }^{5} \mathrm{Ou}$ seja, com recurso à noção de fiabilidade de Goldman (1986), uma vez que as crenças das vítimas do GM são na sua maior parte falsas, então parece que os processos que formam tais crenças não são fiáveis porque tais processos não tendem a produzir maioritariamente crenças verdadeiras.

${ }^{6}$ Esta formalização do argumento é inspirada em Comesaña (2002, p.255).

${ }^{7}$ Neste texto não pretendemos tratar as respostas intuitivamente não-prometedoras para lidar com o problema do novo GM. Por exemplo, uma das respostas de Goldman (1986, pp.107-113) foi defender que o processo de formação de crenças, de modo a fornecer justificação, teria de ser fiável em "mundos normais", i.e., naqueles mundos que se assemelham largamente à forma como o sujeito acredita ser o mundo atual. Ora, tendo isso em conta, as crenças das vítimas do GM estariam justificadas uma vez que são fiáveis em "mundos normais". No entanto, há aqui um grande problema: se uma crença é justificada apenas no caso de ser produzida por um processo que seria fiável nos mundos que são em linhas gerais como o sujeito considera ser o mundo atual, então o que determina se uma crença é justificada é apenas o que sujeito acredita, e isso é uma posição claramente internista. Deste modo, a condição fiabilista deixa de ser uma condição externista, o que vai contra a ideia central de fiabilismo. Contudo, mais tarde o próprio Goldman (1988) reconheceu os problemas dessa resposta e abandonou-a.

${ }^{8}$ Com esta abordagem, a premissa (4) deve ser substituída por: (4') A crença $p$ de um dado agente é justificada só se $p$ é produzida por um processo que é atualmente fiável.

${ }^{9} \mathrm{O}$ fiabilismo indexical parece permitir resolver igualmente o problema do "conhecedor alienígena" identificado por Goldman (1988, p.62), Sosa (2001, p.390), entre outros, ao apontarem a possibilidade de seres alienígenas obterem conhecimento ou estatuto epistémico positivo a partir de processos de formação de crenças fiáveis nos seus mundos, embora tais processos seriam completamente inadequados e não fiáveis no nosso mundo. Ora, de acordo com o fiabilismo indexical, há um sentido em que tais seres estão justificados, pois as suas crenças resultam de processos que são fiáveis nos seus mundos (i.e. eles têm justificação diagonal) e, assim, podem ter conhecimento. Contudo, há também um outro sentido em que 
tais seres não estão justificados, pois as suas crenças resultam de processos que não são fiáveis no nosso mundo atual (i.e. eles não têm justificação horizontal).

${ }^{10}$ Ainda que a conceção de justificação diagonal e horizontal não esteja adequadamente fundamentada na semântica bidimensional, pode mesmo assim fazer sentido estabelecer essa distinção ou alguma bastante similar, tal como sustenta Sosa (1993, pp.60-61; 2001, pp.384-385), ao defender que se pode distinguir uma crença como apta-justificada e como hábil-justificada. Por um lado, $p$ é apta-justificada em $w$ só se $p$ é adquirida em $w$ através do exercício de uma ou mais virtudes que são virtuosas em $w$. Por outro lado, $p$ é hábil-justificada em $w$ só se $p$ é adquirida em $w$ através do exercício de uma ou mais virtudes intelectuais que são virtuosas no mundo atual (indexical). Com esta distinção podemos afirmar que as crenças das vítimas do GM são hábil-justificadas, mas não apta-justificadas.

${ }^{11}$ Graham caracteriza igualmente as "condições normais" como: (i) relativas a espécies, (ii) tipos repetíveis de circunstâncias, (iii) não necessariamente típicas, (iv) podem existir no mundo atual e possíveis, (v) compreendem um subconjunto de todas as condições num mundo.

${ }^{12} \mathrm{O}$ ponto principal é, então, que as crenças de $S^{*}$ estão justificadas mesmo que ele não esteja presentemente numa circunstância normal (por causa do GM), pois $S^{*}$ continua a usar as mesmas capacidades que são fiáveis quando se está em circunstâncias normais para os humanos.

${ }^{13}$ Esta proposta de solução também permite dar uma plausível resposta para problema do "conhecedor alienígena", pois mesmo embora a capacidade psicológica alienígena não seja fiável no mundo atual, é fiável em condições normais, i.e., em condições normais para os alienígenas. Assim, o que acontece ou não no mundo atual é irrelevante para determinar se as suas capacidades psicológicas são procedimentos epistemicamente corretos de formação de crenças.

${ }^{14}$ Littlejohn (2009) tem um argumento similar para esta mesma conclusão.

${ }^{15}$ Vários epistemólogos estabelecem a distinção entre justificação subjetiva e objetiva, tal como Greco (1999, p.285; 2000, p.xiv; 2014, pp.326-327), Goldman (2002, pp.65-66), BonJour e Sosa (2003, pp.36-38; pp.153-155), Vahid (2005, p.8; 2010, pp.144-145), Lackey (2008, pp.10-11), Plantinga (2008, p.177), Carter e Palermos (2016, pp.236-239).

${ }^{16}$ Para uma introdução à condição dos derrotadores (ou de ausência de evidência contrária) veja-se, p.e., Bergmann (2006), BonJour e Sosa (2003).

${ }^{17} \mathrm{O}$ problema da sorte epistémica subjetiva tem a ver com o facto de que crenças resultantes de faculdade ou processos fiáveis podem ser acidentais a partir da perspetiva do sujeito e, dessa forma, tais crenças podem não ter qualquer justificação. Por exemplo, suponha-se que um professor de matemática transmitiu numa dada aula um certo teorema $T$ e um dos seus alunos faltou. Imagine-se igualmente que dias depois, como não queria repetir a mesma matéria na aula seguinte para esse aluno, o professor conseguiu hipnotizá-lo (sem que este se apercebesse) implantando-lhe a crença no teorema $T$ através de um processo especial de hipnose: um processo que ele projetou cuidadosamente para produzir em circunstâncias apropriadas a crença em $T$ de forma fiável (dessa forma, as condições da fiabilidade e da função apropriada são satisfeitas). Após tal facto, o aluno tem a crença firme em $T$, que lhe aparece subitamente à mente, mas não tem qualquer evidência a favor ou contra. Será a crença do aluno em $T$ justificada? Certamente que não. Neste caso o aluno tem uma crença verdadeira que resulta de um processo fiável e que funciona apropriadamente; pois, o "pro-

Principia 21(3): 461-471 (2017). 
cesso" em questão (i.e. a hipnose especial) para se implantar crenças verdadeiras acerca de $T$ está bem projetado para alcançar esse seu propósito na maioria dos casos. Mas, apesar de satisfazer essas condições externistas, a crença do aluno não tem justificação ou estatuto epistémico positivo para ele. Isto porque podemos dizer a crença em $T$ parece, a partir do ponto de vista do aluno, meramente acidental. Para lidar com este ou outros casos similares é preciso adicionar um requisito de evidência à justificação ou ao estatuto epistémico positivo mais elementar.

${ }^{18} \mathrm{~A}$ favor dessa ideia podemos pensar em casos possíveis que são similares com respeito aos fatores internos à perspetiva de $S$, mas diferentes em relação ao estatuto epistémico. Ou seja, casos em que se mantém constantes aquilo que faz parte da perspetiva interna de $S$ (como se possuir a mesma evidência não-factiva), mas em que constatamos diferenças em estatuto epistémico e em que tal diferença se deve a fatores que são externos à perspetiva de $S$. Por exemplo, imagine-se um guarda-florestal solitário vive numa pequena casa nas montanhas e tem do lado de fora da janela um conjunto de sinos de vento pendurados. Ora, quando esses sinos de vento emitem som, o guarda-florestal forma a crença de que o vento está a soprar. A partir deste caso vamos imaginar duas situações diferentes:

(S1) Todas as faculdades cognitivas deste guarda estão a funcionar apropriadamente num ambiente epistémico adequado e quando ele ouve os sinos, forma a crença de que o vento está a soprar (resultante de um processo fiável de formação de crença).

(S2) A audição deste guarda deteriorou-se (sem que ele o soubesse) e, assim, ele não é mais capaz de ouvir os sinos. Além disso, ele é por vezes sujeito a pequenas alucinações auditivas de sinos de vento; e acidentalmente essas alucinações ocorrem quando o vento está a soprar.

Tanto na situação (S1) como na (S2) podemos supor que os fatores que são internos à perspetiva do sujeito são os mesmos, i.e. que o sujeito tem os mesmos estados mentais ou tem acesso privilegiado aos mesmos fatores nas duas situações. Porém, intuitivamente consideramos que o sujeito em (S1) tem um elevado estatuto epistémico positivo na crença de que o vento está a soprar enquanto que em (S2) ele não tem tal grau de estatuto epistémico. Isto porque, ao contrário do que acontece em (S1), a sua crença em (S2) é causada pela sua disfunção cognitiva e revela-se verdadeira por acidente ou por mero acaso. Portanto, não é suficiente para um elevado estatuto epistémico positivo que as condições internistas (como o requisito evidencial) sejam satisfeitas, sendo assim necessário algo externo à perspetiva de $S$.

${ }^{19}$ Alguns casos do tipo Gettier (como o caso do relógio ou do celeiro) são outros exemplos de casos em que não há um ambiente epistémico favorável, apesar de haver justificação subjetiva e objetiva. Por isso, nesses casos não há conhecimento nem estatuto epistémico positivo no grau mais elevado.

Principia 21(3): 461-471 (2017). 